\title{
A Case-Control Study of Apolipoprotein E Genotypes in Alzheimer's Disease Associated with Down's Syndrome
}

\author{
W. A. van Gool, MD, ${ }^{*}$ H. M. Evenhuis, MD, $\dagger$ and C. M. van Duijn PhD, $\ddagger$ on Behalf of the Dutch Study \\ Group on Down's Syndrome and Ageing§
}

The prevalence of clinical signs and neuropathological findings of Alzheimer's disease (AD) is high in Down's syndrome (DS). In the general population, the apolipoprotein $\mathrm{E}$ (ApoE) $\epsilon 4$ isoform is an important risk marker for AD. We studied the allelic frequencies of ApoE in 26 DS cases fulfilling clinical diagnostic criteria for AD and in 26 DS controls matched for age, sex, and premorbid level of mental retardation. A meta-analysis of data available in the literature was used for comparison with allele frequencies in other $\mathrm{AD}$ and control populations. ApoE type 2, 3, or 4 allele frequencies were not significantly different in AD-DS cases and DS controls. The ApoE $\epsilon 4$ frequency in DS cases with AD (0.14; CI, 0.06-0.26) was significantly lower than in any other AD population studied so far and it is within the range of nondemented controls from the general population. These findings suggest that ApoE $€ 4$ does not significantly affect the pathogenesis of AD in DS patients.

van Gool WA, Evenhuis HM, van Duijn CM, on Behalf of the Durch Study Group on Down's Syndrome and Ageing. A case-control study of apolipoprotein E genotypes in Alzheimer's disease associated with Down's syndrome. Ann Neurol 1995;38:225-230

Prevalence estimates of dementia in populations with Down's syndrome (DS) amount to 8,55 , and $75 \%$ in the fifth, sixth, and seventh decades, respectively [1]. In virtually all cases of DS over 40 years of age senile plaques and neurofibrillary tangles characteristic of Alzheimer's disease (AD) are present within one or more regions of the brain [2]. Increased expression of the $\beta$-amyloid precursor gene located on chromosome 21 is thought to underly the development of these abnormalities in trisomy 21 [2].

In the general population, the apolipoprotein $\mathrm{E}$ (ApoE) $\epsilon 4$ isoform is an important risk marker for developing $A D$, and in familial forms of $A D \notin 4 A p o E$ confers an earlier onset of dementia [3]. These observations fostered the hypothesis that $A \mathrm{poE}$ rather than $\beta$-amyloid plays a central role in the pathogenesis of $A D$ [3]. Previous observations on the frequency of $\epsilon 4$ ApoE in DS yielded figures ranging from 0.03 to 0.22 , suggesting that trisomy 21 itself does not segregate with a specific ApoE genotype [4-7]. However, neither of these reports specified whether the DS subjects studied showed clinical signs of $A D$. If an ApoE $\in 4-$ driven process of paired helical filament formation has a primary role in causing clinical and neuropathological signs of $A D$ [8], ApoE genotype can be expected to modulate the risk or age of onset of dementia in DS as well. To investigate this hypothesis, we compared the allelic frequencies of ApoE between DS cases fulfilling clinical diagnostic criteria for $\mathrm{AD}$ and nondemented DS controls. A meta-analysis of data available in the literature was used for comparison with allele frequencies in control and $A D$ populations from the general population.

\section{Materials and Methods}

Subjects were ascertained through eight institutions for persons with mental retardation (specified in the footnotes). Patients were included as AD-DS cases according to the
From the *Academic Medical Center, University of Amsterdam, De-
partment of Neurology, Amsterdam; $†$ Hooge Burch, Zwammerdam;
and $\neq$ Erasmus University, Department of Epidemiology and Biosta-
tistics, Rotterdam, The Netherlands.
$\S$ The following individuals, members of the Dutch Study Group on
Down's syndrome and Ageing, and institutions contributed to this
study by referring patients: Dr A. M. W. Coppus (Maria Roepaan,
Ottersum), Dr K. W. Dollekens (De Donksbergen, Duizel), Dr
H. I. de Jonge (Eckartdal, Eindhoven), Dr C. van Schie and Dr
H. Steegemans (both, Severinusstichting, Eindhoven), Dr H. van der Stal (Vijverveugd, Middeiburg), Dr F. E. Visser ('s-Heeren LooLozenourd, Ermelo), all in The Netherlands, and Dr P. Brucker and Dr P. B. Berry (Neuerkerode, Sickte) in Germany. Technical assistance and advice was provided by Dr P. A. Bolhuis (AMC, Amsterdam), Prof P. Eikelenboom (PCA/Valeriuskliniek, Amsterdam), and G. W. Hensels (AMC, Amsterdam).

Received Mar 24, 1995. Accepted for publication Apr 20, 1995.

Address correspondence to Dr van Gool, Department of Neurology, Academic Medical Center, University of Amsterdam, PO Box 22700, I100 DE Amsterdam, The Netherlands. 
following criteria: (1) a diagnosis of DS based on karyotyping; (2) a clinical diagnosis of dementia based on evidence for memory disturbances combined with aphasia, apraxia, changes in the original level of spatial or temporal orientation, or personality changes, all based on longitudinal observations in daily circumstances, interfering with work or usual social activities or personal relationships, not occurring exclusively during the course of delirium; (3) a score of 20 or more or increase of 7 points or more on the cognitive subscale of the Dementia Questionnaire for Mentally Retarded Persons [9]; (4) an estimated time since onset of symptoms of at least 1 year; (5) absence of abnormalities on medical, psychiatric, neurological, and laboratory examination explaining the mental deterioration; especially severe hearing loss and hypothyroidism were excluded. Subjects were classified as DS control on the basis of (1) a karyotype-verified diagnosis of DS; (2) absence of dementia, indicated by absence of changes in functioning in daily circumstances in the period preceding inclusion. Subjects were classified as AD cases or controls by physicians who knew the patients for years before the beginning of this study. Cases and controls were matched for sex, age, and for premorbid level of functioning on the basis of scores on a Dutch standard instrument measuring adaptive functioning, used in all participating institutions [10]. Approval for the study was obtained from the ethics review committees of all participating institutions (see footnotes). In all participants consent was obtained from relatives and if possible from the subjects themselves. Resistance of participants to venapuncture, either in words or actions, was interpreted as withdrawal of consent leading to exclusion from the study,

Genomic DNA samples were prepared from peripheral white blood cells. ApoE genotyping was performed in the coordinating center on coded samples withour knowledge of the clinical diagnosis. About I to $2 \mu \mathrm{g}$ of DNA was isolated from $20 \mathrm{ml}$ EDTA-blood. ApoE genotype was determined using a modification of the method of Hixson and collaborators [11]; to visualize ApoE genotypes on agarose gel the $3^{\prime}$-primer was elongated with a 20 -nucleotide AT tail (Reymer PWA, Groenemeyer BE, van de Burg R, Kastelein JJP, unpublished data). Polymerase chain reactions ( $P C R s$ ) were carried out in standard buffer $(50 \mathrm{mM} \mathrm{KCl}, 10 \mathrm{mM}$ Tris-OH, $\mathrm{pH} 9.0,0.01 \%$ gelatin, $1.5 \mathrm{mM} \mathrm{MgCl}_{2}, 0.1 \%$ Triton X-100) with $0.5 \mu \mathrm{M}$ concentration of primer, $100 \mu \mathrm{M} \mathrm{dNTP}$, and $0.2 \mathrm{mg} / \mathrm{ml}$ bovine serum albumin. After amplification (without dimethyl sulfoxide; 30 seconds at $94^{\circ} \mathrm{C}, 1$ minute at $60^{\circ} \mathrm{C}$, 1 minute at $70^{\circ} \mathrm{C}, 30$ cycles with 0.5 units Supertaq [Sphaero-Q, UK]) and digestion with 4 units $C$ fol ([Promega, USA] 1.5 hour at $37^{\circ} \mathrm{C}$ ) PCR/digestion fragments could be separated on a $5 \%$ agarose gel (Agarose MP, Boehringer Mannheim, Germany) and visualized by ethidium bromide staining (Reymer PWA, Groenemeyer BE, van de Burg R, Kastelein JJP, unpublished data). Prior power calculations showed that a minimum of 50 alleles should be studied in each group to detect at least a twofold excess of ApoE $\epsilon 4$ in AD-DS compared with DS controls, with an $\alpha$ - and $\beta$-error of 0.05 and 0.10 , respectively.

For the meta-analysis of $\mathrm{ApoE}$ allele frequencies in controls and $\mathrm{AD}$ patients from the general population, a computer search in Medline for the period August 1993 to Octo- ber 1994 was performed using "apolipoprotein E" and "Alzheimer's disease" as search terms. Retrieved articles or letters to the editor, excluding abstracts, in which original research was described were identified. We only included studies if (1) well-described diagnostic criteria for AD were used, (2) data presentation was in such a manner that $\epsilon 4$ ApoE allele frequencies could be calculated, and (3) the AD group contained at least 25 parients.

Allele frequencies were estimated by counting alleles and calculating sample proportions. Comparisons of genotype frequencies and allele frequencies were made using the $x^{2}$ statistic or Fisher's exact test, as appropriate. Differences in age of onset and duration of symptoms according to the presence of the $\epsilon 4$ allele in AD-DS cases were analyzed statistically by the unpaired $t$ test.

\section{Results}

A total of 52 subjects with DS were included in the study. There were no significant differences between the AD-DS cases and DS controls in age, sex, and premorbid level of functioning (Table 1). The frequency of the most common genotype (ApoE 3/3) was similar in both groups. The ApoE type 2, 3, and 4 allele frequencies were not significantly different in AD-DS cases and DS-control subjects (see Table 1). Age of onset in AD-DS with (mean $[ \pm \mathrm{SD}], 54.1$ [ 7.9] years) and without $\epsilon$-alleles $(54.6[ \pm 6.5]$ years) was not significantly different ( $p=0.86$ ). Also the duration of symptoms in $\in 4$-carriers $(3.6[ \pm 1.7]$ years) was similar to those without the 64 -allele $(4.9[ \pm 2.7]$ years) $(p=0.25)$.

The results of the meta-analysis of studies performed in non-DS populations showed increased ApoE $\epsilon 4$ allele frequencies in all cohorts with $A D$, which were most prominent in those with familial onset and with lateonset of AD (Table 2 and Fig). The ApoE $\epsilon 4$ frequency found in the AD-DS cases is significantly lower than in any other AD population studied so far, and it is within the range of published general population data on nondemented subjects (see Table 2 and Fig) [12].

\section{Discussion}

Since the pivotal observations of the Duke University group on the association between the ApoE $\epsilon 4$ allele and $A D[6,19,20,22,23]$, numerous studies have replicated this finding in various populations of $A D$ patients with different hereditary components, ages of onset, and ethnic backgrounds (see Fig for references). The $\epsilon 4$ ApoE allele frequency in the AD-DS cases described here is particularly interesting because it is the first clinically diagnosed $\mathrm{AD}$ population of reasonable size in which such low figures were found. In our population of AD-DS cases of ApoE $\epsilon 4$ frequency was only slightly higher than in nondemented DS controls 
Table 1. Patient Characteristics, ApoE Genotypes, and Allele Frequencies

\begin{tabular}{|c|c|c|c|c|}
\hline & \multicolumn{2}{|c|}{ DS Controls } & \multicolumn{2}{|c|}{$\mathrm{AD}-\mathrm{DS}$} \\
\hline Number of subjects & \multicolumn{2}{|l|}{26} & \multicolumn{2}{|c|}{26} \\
\hline Age $(y r)(S D$, range $)$ & \multicolumn{2}{|c|}{$55.0(8.6,41-70)$} & \multicolumn{2}{|c|}{$54.5(7.4,42-71)$} \\
\hline \multirow[t]{2}{*}{ Men/Women } & \multicolumn{2}{|c|}{$10 / 16$} & \multicolumn{2}{|c|}{$10 / 16$} \\
\hline & $\mathrm{n}$ & Frequency $(95 \% \mathrm{Cl})$ & $\mathrm{n}$ & Frequency $(95 \% \mathrm{CI})$ \\
\hline \multicolumn{5}{|l|}{ Level of retardation } \\
\hline Profound & 1 & $0.04(0.00-0.20)$ & I & $0.04(0.00-0.20)$ \\
\hline Severe & 16 & $0.62(0.41-0.80)$ & 17 & $0.65(0.44-0.83)$ \\
\hline Moderate & 9 & $0.35(0.17-0.56)$ & 8 & $0.31(0.14-0.52)$ \\
\hline \multicolumn{5}{|l|}{ Genotype } \\
\hline $4 / 4$ & - & - & - & - \\
\hline $3 / 3$ & 17 & $0.65(0.44-0.83)$ & 16 & $0.62(0.41-0.80)$ \\
\hline $2 / 2$ & 1 & $0.04(0.00-0.20)$ & - & - \\
\hline $4 / 3$ & 4 & $0.15(0.04-0.35)$ & 7 & $0.27(0.12-0.48)$ \\
\hline $4 / 2$ & 1 & $0.04(0.00-0.20)$ & - & - \\
\hline $2 / 3$ & 3 & $0.12(0.03-0.30)$ & 3 & $0.12(0.03-0.30)$ \\
\hline \multicolumn{5}{|l|}{ Allele frequencies } \\
\hline$\epsilon 2$ & 6 & $0.12(0.04-0.23)$ & 3 & $0.06(0.01-0.16)$ \\
\hline$\epsilon 3$ & 41 & $0.79(0.65-0.89)$ & 42 & $0.81(0.68-0.90)$ \\
\hline$\epsilon 4$ & 5 & $0.10(0.03-0.21)$ & 7 & $0.14(0.06-0.26)$ \\
\hline
\end{tabular}

ApoE $=$ apolipoprotein $\mathrm{E} ; \mathrm{DS}=$ Down's syndrome; $\mathrm{AD}=$ Alzheimer's disease $\mathrm{CI}=$ confidence interval.

Table 2. ApoE $\epsilon 4$ Allele Frequencies in Different $A D$ and Control Populations

\begin{tabular}{|c|c|c|c|}
\hline \multicolumn{2}{|l|}{ Study Population } & \multicolumn{2}{|c|}{ ApoE $\in 4$ Allele } \\
\hline Type & $\mathrm{n}$ & Frequency & $95 \% \mathrm{CI}$ \\
\hline Early onset familial $\mathrm{AD}^{\mathrm{a}}$ & 286 & $0.42^{\mathrm{d}}$ & $0.36-0.48$ \\
\hline Early onset sporadic $\mathrm{AD}^{\mathbf{a}}$ & 336 & $0.28^{\mathrm{e}}$ & $0.23-0.33$ \\
\hline Late onset familial $\mathrm{AD}^{\mathrm{a}}$ & 1,202 & $0.48^{f}$ & $0.45-0.51$ \\
\hline Late onset sporadic $\mathrm{AD}^{\mathrm{a}}$ & 3,124 & $0.37^{\mathrm{g}}$ & $0.35-0.39$ \\
\hline Nondemented controls ${ }^{b}$ & 2,000 & 0.14 & $0.12-0.16$ \\
\hline DS controls ${ }^{c}$ & 52 & 0.10 & $0.03-0.21$ \\
\hline AD-DS cases ${ }^{c}$ & 52 & 0.14 & $0.06-0.26$ \\
\hline
\end{tabular}

${ }^{3}$ Results from meta-analysis (see Materials and Methods and Fig).

${ }^{\mathrm{b}}$ Taken from Menzel and co-workers [12] (see also Fig). This group served as reference for comparison of apolipoprotein $E$ (ApoE) $\epsilon 4$ allele frequencies in the other groups using the $x^{2}$ statistic.

'This study (see also Fig and Table 1).

${ }^{d} x^{2}=136.7, d f=1, p<0.0001$.

${ }^{e} x^{2}=40.6, d f=1, p<0.0001$.

${ }^{1} x^{2}=118.5, d f=1, p<0.0001$.

${ }^{2} \chi^{2}=320.3, d f=1, p<0.0001$.

$\mathrm{AD}=$ Alzheimer's disease $\mathrm{CI}=$ confidence interval $; \mathrm{DS}=$ Down's syndrome. and it was similar to that in nondemented controls from the general population [12]. Several explanations may account for this unexpected observation.

First, difficulties in diagnosing $A D$ in the general population are well established and diagnosing this condition in individuals with mental retardation is even more difficult than in persons with normal intelligence and psychosocial functioning [41]. Applying diagnostic criteria designed for populations without mental retardation may elicit numerous false-positive classifications if used in a DS population. This may lead to underestimation of real differences in $\epsilon 4$ allele frequencies between AD-DS and DS controls. However, to minimize the risk of bias we studied institutionalized patients, which enabled us to use criteria relying heavily on long-standing, careful observations in daily life, using comparison with former actual levels of psychosocial functioning, rather than applying a single clinical and neuropsychological assessment. Also careful exclusion of various conditions other than $A D$ that can impair the level of functioning in persons with DS should have minimized diagnostic misclassifications. Second, excess mortality in AD-DS cases carrying $\epsilon 4$ alleles may have obscured hypothetical true differences between cases and controls. However, we found no effects of the $\epsilon 4$ allele presence on disease duration, rendering this explanation unlikely. Moreover, the $\epsilon 4$ allele frequencies in AD-DS cases and in DS controls reported here are within the range of those found in 


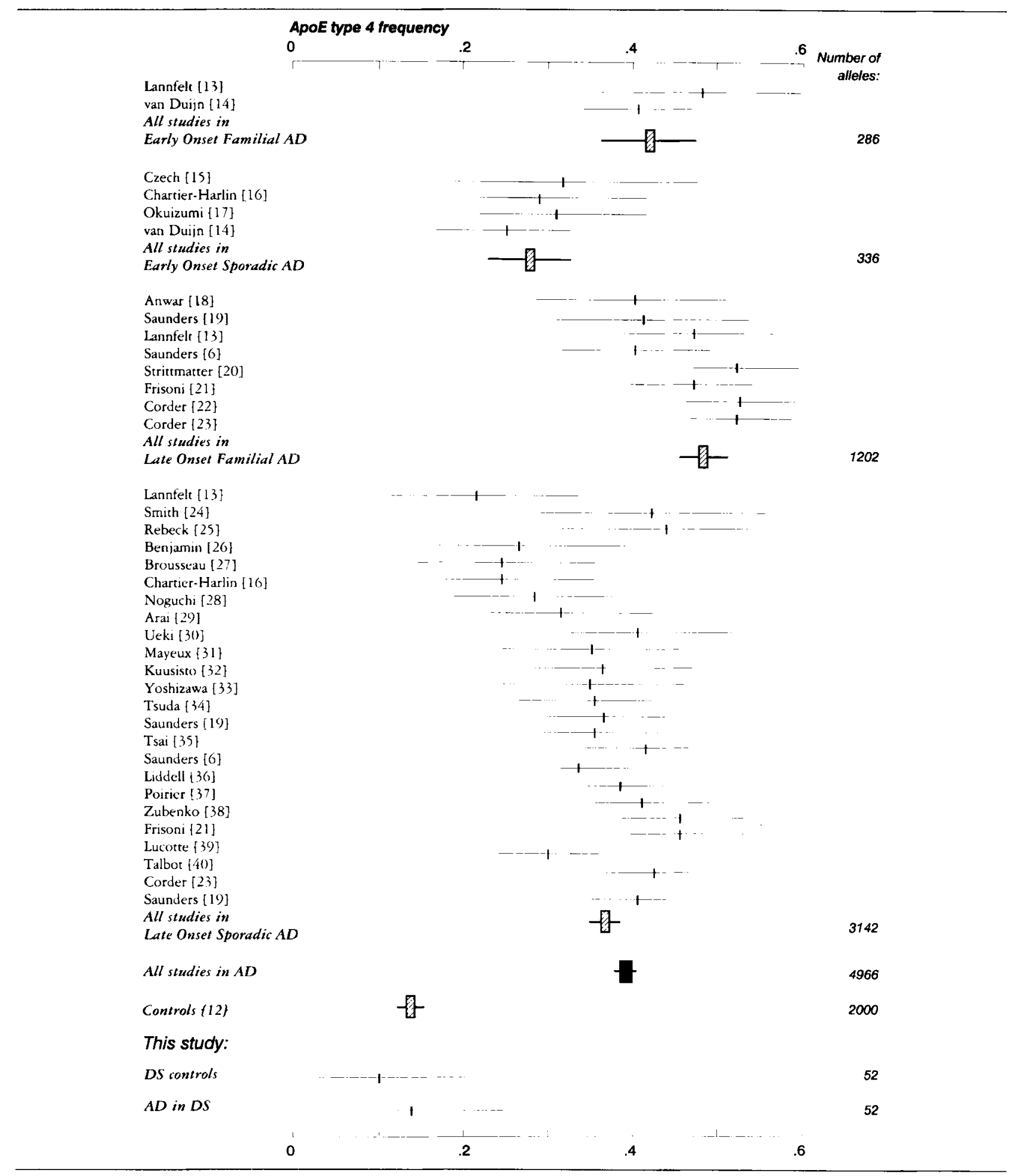

Apolipoprotein E (ApoE) $\epsilon 4$ allele frequencies and $95 \%$ confidence internals in different studies ordered according to the type of population studied and, within a category, to study size. First authors and reference are indicated on the left and the number of alleles studied on the right. $A D=$ Alzbeimer's disease: $D S=$ Doun's syndrome. 
other populations with trisomy $21[4-7]$. The possible relation between ApoE phenotypes and dementia in DS remained unclear in these previous studies, because the mental status of the subjects was not evaluated.

That we were unable to detect significant differences in $\epsilon 4$ allele frequency between demented and nondemented persons with DS, between patients with early and late onset of dementia, and between AD-DS cases with short and long duration of dementia symptoms is consistent with the view that the clinical and neuropathological signs of AD in trisomy 21 should mainly be attributed to increased formation of $\beta$-amyloid. Apparently ApoE $\epsilon 4$ does not further increase the high risk of developing $\mathrm{AD}$ in $\mathrm{DS}$. Despite the fact that ApoE is present in senile plaques in AD-DS [42], the $\epsilon 4$ isotype of this protein appears neither to influence the clinical expression (this study) nor the neuropathological features of this disease in DS $[4,5,7]$, suggesting that the relative contribution of either ApoEor $\beta$-amyloid-driven processes in the pathogenesis of $\mathrm{AD}$ differs between populations with trisomy 21 and those with a normal karyogram. This difference provides additional support for the idea that $A D$ is an etiologically heterogeneous disorder, which is also exemplified by the presence of sporadic forms of $A D$, autosomal dominant forms with mutations in the chromosome 21 amyloid precursor protein (APP) gene, and familial forms of $\mathrm{AD}$ with linkage to chromosomes 14 and 19, and to another unidentified locus [43].

A population with such a high risk for developing $\mathrm{AD}$, as the DS population studied here, is extremely suitable to study putative protective factors for not developing $A D$. Several studies suggest that $\epsilon 2 \mathrm{ApoE}$ may reduce the risk of developing $\mathrm{AD}[23,24,26$, 40]. This observation led to the hypothesis that ApoE genotypes may modulate the risk for $\mathrm{AD}$ by differentially affecting the rate of phosphorylation of $\tau$ to form neurofibrillary tangles [3]. According to this hypothesis $\epsilon 4$ ApoE would stimulate tangle formation, whereas $\epsilon 2$ would protect against neurofibrillary degeneration. However, we found no excess $\epsilon 2$ alleles in our DS controls, not even among the 14 elderly nondemented DS individuals over 55 years of age $(0.15 \notin 2$ alleles; confidence interval $[\mathrm{CI}], 0.04-0.35)$. Our study was initially designed to study differences in $\epsilon 4$ allele frequencies, and given the low prevalence of $\epsilon 2$ alleles, the power of our study may have been too limited to draw any conclusion concerning the absence of a protective allele $\epsilon 2$ effect in this specific population.

Apart from these considerations relating to the pathogenesis of $\mathrm{AD}$, the present results may also have practical implications. When the first reports on the excess of $\epsilon 4$ alleles in $A D$ appeared, several authors suggested that ApoE genotyping could be a tool for identifying individuals with increased risk for developing $\mathrm{AD}[28,30,35,44,45]$ although preliminary analyses already predicted that the practical usefulness of ApoE genotyping for such a purpose will be poor in the general population $[46,47]$. Based on our present results it can be concluded that $A$ poE genotyping for diagnostic purposes will certainly not be feasible in DS populations. In a similar manner, it has been speculated that manipulation of the ApoE-driven pathogenetic pathways may offer new therapeutic opportunities $[17$, $40,44,48]$, whereas the present results strongly suggest that it is not useful to pursue such efforts in AD-DS parients.

In conclusion, whatever the relative contribution of either ApoE or $\beta$-amyloid in the pathogenesis of AD may be in the general population, the absence of excess of $\epsilon 4$ alleles in AD-DS patients as documented in our study suggests that the role ApoE $€ 4$ plays in causing $A D$ in individuals with $D S$ is of minor importance. This conclusion may have implications for future studies into diagnostic and therapeutic efforts in AD-DS and it reinforces the idea that $\mathrm{AD}$ is an etiologically heterogeneous disorder.

\section{References}

1. Lai F, Williams RS. A prospective study of Alzheimer disease in Down syndrome. Arch Neurol 1989;46:849-853

2. Mann DMA. Association between Alzheimer disease and Down syndrome: neuropathological observations. In: Berg JM, Karlinsky $\mathrm{H}$, Holland AJ, eds. Alzheimer disease, Down syndrome, and their relationship. Oxford: Oxford University Press, 1993 $71-92$

3. Roses AD. Apolipoprotein $\mathrm{E}$ affects the rate of Alzheimer disease expression: beta-amyloid burden is a secondary consequence dependent on APOE genotype and duration of disease. J Neuropathol Exp Neurol 1994:53:429-437

4. Pickering-Brown SM, Mann DM, Bourke JP, et al. Apolipoprotein E4 and Alzheimer's disease pathology in Lewy body disease and in other beta-amyloid-forming diseases. Lancet 1994;343:1155 (Letter)

5. Hardy J, Crook R, Perry R, et al. ApoE genotype and Down's syndrome. Lancet 1994;343:979-980

6. Saunders AM, Schmader K, Breitner JCS, et al. Apolipoprotein $\mathrm{E}$ rype 4 allele distributions in late-onset Alzheimer's disease and in other amyloid-forming diseases. Lancet 1993;342:710-711

7. Wisniewski T, Morelli $L$, Wegiel J, et al. The influence of apolipoprotein $\mathrm{E}$ isotypes on Alzheimer's disease pathology in 40 cases of Down's syndrome. Ann Neurol 1995;37:136-138

8. Strittmatter WJ, Weisgraber KH, Goedert M, et al. Hypothesis: microtubule instability and paired helical filament formation in the Alzheimer disease brain are relaced to apolipoprotein $\mathrm{E}$ genotype. Exp Neurol 1994;125:163-171

9. Evenhuis HM. Evaluation of a screening instrument for dementia in ageing mentally retarded persons. J Intellectual Dis Res 1992;36:337-347

10. Krajjer DW, Kema GN. Sociale Redzaamheidsschaal voor Zwakzinnigen. Lisse: Swets and Zeitlinger, 1985

11. Hixson JE, Vernier DT. Restriction isotyping of human apolipoprotein $\mathrm{E}$ by gene amplification and cleavage with hha-1. J Lipid Res 1990;31:545-548

12. Menzel H-J, Kladerzky R-G, Assmann G. Apolipoprotein E 
polymorphism and coronary heart disease. Arteriosclerosis $1983 ; 3: 310-315$

13. Lannfelt L, Lilius L, Nastase $M$, et al Lack of association between apolipoprotein $\mathbf{E}$ allele epsilon 4 and sporadic Alzheimer's disease. Neurosci Lett 1994;169:175-178

14. van Duijn $C M$, de Knijff $P$, Cruts $M$, et al. Apolipoprorein E4 allele in a population-based study of early-onset Alzheimer's disease. Nat Genet 1994;7:74-78

15. Czech C, Monning V, Tienari PJ, et al. Apolipoprotein Eepsilon 4 allele and Alzheimer's disease. Lancet 1993;342:1309 (Letter)

16. Chartier-Harlin MC, Parfitt M, Legrain S, et al. Apolipoprotein E, epsilon 4 allele as a major risk factor for sporadic early and late-onset forms of Alzheimer's disease: analysis of the $19 \mathrm{q} 13.2$ chromosomal region. Hum Mol Genet 1994;3:569-574

17. Okuizumi $\mathrm{K}$, Onodera $\mathrm{O}$, Tanaka $\mathrm{H}$, et al. ApoE-epsilon 4 and early-onset Alzheimer's. Nat Genet 1994;7:10-11 (Letter)

18. Anwar N, Lovestone S, Cheetham ME, et al. Apolipoprotein E-epsilon 4 allele and Alzheimer's disease. Lancet 1993:342: 1308-1309

19. Saunders AM, Strittmatter WJ, Schmechel D, et al. Association of apolipoprotein $\mathrm{E}$ allele epsilon 4 with late-onset familial and sporadic Alzheimer's disease. Neurology 1993;43:1467-1472

20. Strittmatter WJ, Saunders AM, Schmechel D, et al. Apolipoprotein E: high-avidity binding to beca-amyloid and increased frequency of type 4 allele in late-onset familial Alzheimer disease. Proc Natl Acad Sci USA 1993;00:1977-1981

21. Frisoni GB, Geroldi C, Bianchetri A, et al. Apolipoprotein E epsilon 4 allele frequency in vascular dementia and Alzheimer's disease. Stroke 1994;25:1703-1704

22. Corder EH, Saunders AM, Strittmatter WJ, et al. Gene dose of apolipoprotein E type 4 allele and the risk of Alzheimer's disease in late onset families. Science 1993:261:921-923

23. Corder EH, Saunders AM, Risch NJ, et al. Protecrive effect of apolipoprotein $\mathbf{E}$ type 2 allele for late onset Alzheimer disease. Nat Genet 1994;7:180-184

24. Smith AD. Johnston C, Sim E, et al. Protecrive effect of apo epsilon 2 in Alzheimer's disease. Oxford Project to Investigate Memory and Ageing (OPTIMA). Lancet 1904;344:473-474

25. Rebeck GW, Perls TT, West HL, et al. Reduced apolipoprotein epsilon 4 allele frequency in the oldest old Alzheimer's patients and cognitively normal individuals. Neurology 1994;44:15131516

26. Benjamin R, Leake A, Edwardson JA, et al. Apolipoprotein E genes in Lewy body and Parkinson's disease. Lancet 1994;343: 1565

27. Brousseau T, Legrain S, Berr C, et al. Confirmation of the epsilon 4 allele of the apolipoprotein $E$ gene as a risk factor for late-onset Alzheimer's disease. Neurology 1994;44:342-344

28. Noguchi S, Murakami K, Yamada N. Apolipoprorein E genotype and Alzheimer's disease. Lancet 1993;342:737 (Letter)

29. Arai H, Muramatsu T, Higuchi S, et al. Apolipoprotein E gene in Parkinson's disease with or without dementia. Lancet 1994; 344:889 (Letter)

30. Ueki A, Kawano M, Namba $Y$, et al. A high frequency of apolipoprotein E4 isoprotein in Japanese patients with late-onset nonfamilial Alzheimer's disease. Neurosci Lett 1993:163:166168

31. Mayeux R, Stern Y, Ottman R. et al. The apolipoprotein epsilon 4 allele in patients with Alzheimer's clisease. Ann Neurol 1993; $34: 752-754$

32. Kuusisto J, Koivisto K, Kervinen K, et al. Association of apolipoprotein $\mathbf{E}$ phenotypes with late onset Alzheimer's disease: population based study. Br Med J 1994;309:636638

33. Yoshizawa T, Yamakawa-Kobayashi K, Komatsuzaki Y, et al. Dose-dependent association of apolipoprotein $\mathrm{E}$ allele type 4 with late-onset, sporadic Alzheimer's disease. Ann Neurol 1994; 36:656-659

34. Tsuda T, Lopez R, Rogaeva EA, et al. Are the associations between Alzheimer's disease and polymorphisms in the apolipoprotein $\mathrm{E}$ and the apolipoprotein $\mathrm{CII}$ genes due to linkage disequilibrium? Ann Neurol 1994;36:9?-100

35. Tsai MS, Tangalos EG, Petersen RC, et al. Apolipoprotein E: risk factor for Alzheimer disease. Am J Hum Genet 1994;54: 643-649)

36. Liddell M, Williams J, Bayer A, et al Confirmation of association between the $\varepsilon 4$ allele of apolipuprotein $\mathrm{E}$ and Alzheimer's disease. J Med Genet 1994;31:197-200

37. Poirier J, Davignon J, Bouthillier 1), et al. Apolipoprotein E polymorphism and Alzheimer's disease. Lancet 1993;342:69769)

38. Zubenko GS, Stiftler S, Stabler S, ct al. Association of the apolipoprotein $E$ type 4 allele with clinical subtypes of autopsyconfirmed Alzheimer disease. Am I Med Genet 1994;54:199205

39. Lucotte G, David F, Visvikis S, et al. Apolipoprotein E-epsilon 4 allele and Alzheimer's disease. Lancet 1993:342:1309

40. Talbot C, Lendon C. Craddock N, et al. Protection against Alzheimer's distease with apoE epsilon 2. Lancet 1994:343:14321433

41. Evenhuis HM. The natural history of dementia in Down's syndrome. Arch Neurol 1990;47:263-267

42. Wisniewski T, Frangione B. Apolipoprotein E: a pathological chaperone protein in patients with cerebral and systemic amyloid. Neurosci Lett 1992;135:235-238

43. Selkoe DJ. Alzheimer's disease: a central role for amyloid J Neuropathol Exp Neurol 1994;53:4,38-447

44. Czech C, Forst H, Hentschel F, et al. Apolipoprotein E-4 gene dose in clinically diagnosed Alzheimer's discase: prevalence, plasma cholesterol levels and cerebrovascular change. Eur Arch Psychiatry Clin Ncurosci 1994:243:291-292

45. Roses AD, Strittmatter WJ, Pericak-Vance MA, et al. Clinical application of apolipoprotein E genotyping to Alzheimer's disease. Lancet 1994;343:1564-1565

46. van Gool WA, Hijdra A. Diagnosis of Alzheimer's disease by apolipoprotein $\mathrm{E}$ genotyping. Lancet 1994;344:275 (Letter)

47. Ben-Shlomo Y, Lewis G, McKeigue PM. Apolipoprotein Eepsilon 4 allele and Alzheimer's discase. Lancet 1993:342:1310 (Letter)

48. Goedert M, Strittmatter WJ, Roses AD. Risky apolipoprotein in brain. Nature 1994;372:45-46 